UC-15

lasued: June 1982

LA --9173

DE82 019498

\title{
A Review of Effectiveness-Evaluation Methodologies for Safeguards and Security Systems
}

Edward J. Dowdy

Dennis L. Mangan*

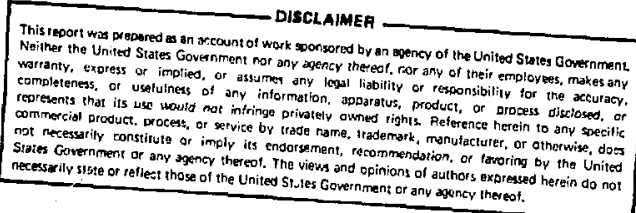

"Sandia National Laboratories, Albuquerque, NM 87185.

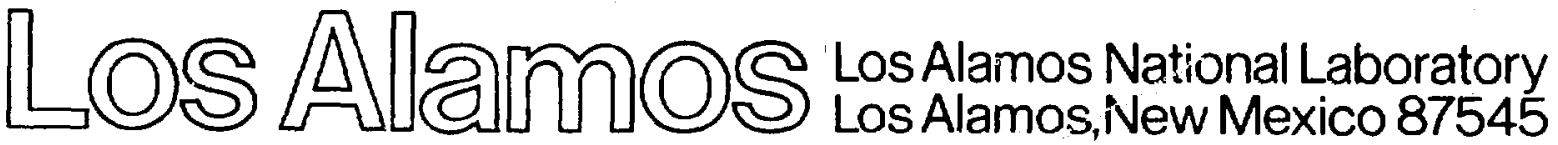


I. GENERAL COMMENTS ON EFFECTIVENESS EVALUATIONS . . . 2

A. Objectlves . . . . . . . . . . . . . . . . . 2

B. Stratification of Requirements . . . . . . . . . . 2

C. Effectiveness Determination ....... . . . . . . . 3

D. Motivation for Methodology Development . . . . . . . . 4

E. Methodology Development Difficulties . . . . . . . . . 4

F. Methodology User Requirements . . . . . . . . . . 5

II. REVIEW PROCEDURES . . . . . . . . . . . . . . . . 5

III. CONCLUSIONS AND RECOMMENDATIONS . . . . . . . . . . 7

A. Physical Protection and Meterial Control . . . . . . . . . . 8

1. Recommendations for Applying Effectiveness

Evaluations to Physical Protection Systems . . . . . . 10

2. Recommendations for Future Activities . . . . . . . 10

B. Material Control and Accountability . . . . . . . . . . 11

1. Recommended Activities Preparatory to Using

MC\&A Evaluation Methodologies . . . . . . . . . . 13

2. Recommendations for Use of These Methodologies . . . . 13

3. Recommendations for Further Development . . . . . . 14

APPENDIX A: EVALUATION METHODOLOGIES FOR

PHYSICAL SECURITY ................. 15

I. EASI ................. 15

II. BATLE .................. 16

III. FESEM .. . . . . . . . . . . . . . . . . . . . . . . . 16

IV. SAFE. . . . . . . . . . . . . . . . . . . . . . . 17

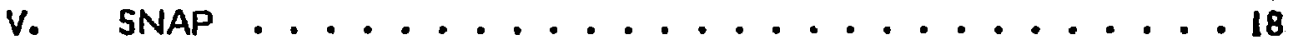

VI. SSPAM .................................. 19

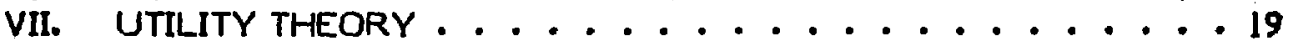

VIII. VISA . . . . . . . . . . . . . . . . . . . . . . . . 20

IX. ISEM . . . . . . . . . . . . . . . . . . . . . . . . . . . 21

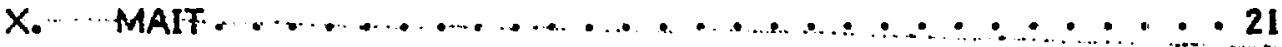

APPENDIX B: EVALUATION METHODOLOGIES FOR

MATERIAL CONTROL AND ACCOUNTABILITY . . . . . . . 23

I. DPA ................... 23

II. IDVA .................. 24

III. MCLAMS .................... 24

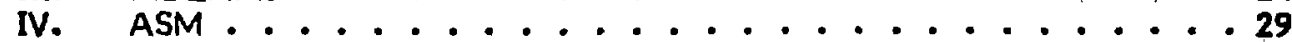

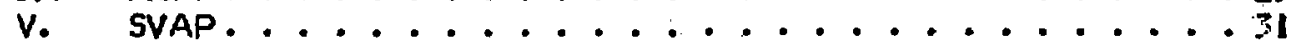

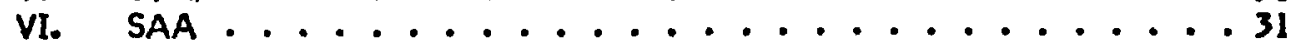

VII. CEP .................... 32

VII. LOS ALAMOS DESIGN AND EVALUATION METHODOLOGY . . . 33

IX. LIVERMORE DESIGN AND EVALUATION METHODOLOGY . . . . 35

REFERENCES .................... 36

GLOSSARY ....................40 


\title{
A REVIEW OF EFFECTIVENESS EVALUATION METHODOLOGIES \\ FOR SAFEGUARDS AND SECURITY SYSTEMS
}

\author{
by
}

Edward J. Dowdy and Dennis L. Mangan

\begin{abstract}
We discuss the factors that influence the effectiveness of safeguards and security measures and the characteristics required of effectiveness evaluation methodologies. Within this context and from a utility standpoint, we review those effectiveness evaluation methodologies that have been developed. Our principal recommendation concerns the application and concomitant validation of existing methodologies. This recommendation derives from our conclusion that there has been a gross imbalance between the effort spent on methodology development and the application of those methodologies. Only for those safeguards measures that do not seem to be covered by existing methodologies or that seem to be inadequately covered do we suggest development.
\end{abstract}

This report presents our conclusions and recommendations resulting from a study, concluded in Jabuary 1980, of effectiveness evaluation methodologies for safeguards and security systems. The study examiñed evaluation methodologies, either extant or being developed, and assessed the lisefulness to the Depertment of Energy Office of Safeguards and Security (DOE/OSS) of such methodologies for performing an adequate and meaningful system evaluation.

This report is structured as followse first, we provide what we perceive to be factors that influence the effectiveness and effectiveness evaluations of safeguards and security systems; second, we briefly describe the review pracedures used in our study; and last, we present our conclusions and recommendations. Appendixes $A$ and $B$ describe the methodologies we examined. 


\section{GENERAL COMMENTS ON EFFECTIVENESS EVALUATIONS}

\section{A. Objectives}

An integrated domestic safeguards system has several objectives. Such a safeguards system should deter potential adversaries from initiating or continuing acts involving the illegal use (including sabotage) of special nuclear material (SNM). It should likewise prevent the completion of such acts by cietecting attempts to obtain SNM and responding to preclude the theft or to recover any SNM taken in successful attempts. These objectives are derived from the basic responsibility to ensure against a significant increase in the overall risk of death, injury, or property damage to the public from other causes beyond the control of the individual.

A comprehensive safeguards program consists, therefore, of deterrence, prevention, response, and recovery functions. The safeguards system fails only upon completion of a malevolent act involving SNM; the opportunity for recovering it exists until the completion of the act. The responsibilities for developing e comprehensive safeguards system are shared, consequently, by soveral separate organizations. The operators of firms involved in the production, transportation, and use of SNM are responsibje for operating in full compliance with orders or regulations. The responsibility for providing laws, regulations, and guidance suitable for adequate safeguards measures rests with the regulating and licensing agencies. Local, regional, and national law enforcement, intelligence and governing agencies, and networks are relied on, under suitable memoranda of understanding and working arrangements, for assistance in providing adequate safeguards measures.

\section{B. Stratification of Requirements}

Because the responsibilities for domestic safeguards are shared, with relatively clear divisions, among several organizations, the requirements for determining the adequacy of the system may differ among these organizations. For instance, the regulating and licensing agencies--DOE, Nuclear Regulatory Commission (NRC), and Department of Defense (DoD)--are interested in determining if the policies, orders, regulations, and contingency plans are appropriate to assure adequacy and if the regulated organizations or licensees are in compliance with these measures. . The regulated-organizationts and licensees must have a mechanism or format for demonstrating compliance with regulations and for detecting vulnerabilities. The regulating and licensing agencies also should be capable of testing the terms of agreements, authorizations, and actions established in the memoranda of understanding and working arrangements with the law enforcement, intelligence, and governing bodies. This indicates a degree of stratification in the requirements for effectiveness evaluation methodologies. Indeed, the degree of stratification just outlined does not meet all of the postulated objectives of effectiveness evaluations. In addition to the need for determining the adequacy of an as-built safeguards system, the results of effectiveness evaluations also can be used to identify research and development rieeds and defend budgets based on such needs and to determine safeguards and security design criteria for new facilities. 
Safeguarding of nuclear weapons production, deployment and emplacement facilities and activities, and nuclear fuel-cycle facilities require the judicious and balenced use of physical security systems, material control and accountability (MC\&A) systems, and safeguards management programs. Of fundamental importance and concern is determining the adequacy of the integrated safeguards system. The identification of vulnerabilities in a safeguards system is a difficult tesk. However, a combination of vulnerability assesaments and the determination of performance capabillties constitute an activity that is tantamount to ascertaining the adequacy of the safeguards system.

\section{Effectiveness Determination}

Safeguards systems effectiveness should be measured in relation to the stated objectives, the perceived threat against the safeguarded facility, and the consequences of failure of the safeguards system. The perceived threat is generated by the analyses of related historical illegal activities and active intelligence information and estimates, based on projections, of potential adversary characteristics and capabilities. Consideration of the attractiveness of the target SNM to the adversary, the difficulty in obtaining the SNM and converting it to a form suitable for the adversary's purpose, and the consequences of its malevolent use result in what has been characterized as a graded safeguards system.

It has been assumed, for exampie, that the consequences of detonating an Improvised nuclear device (INC), even one of very low-order nuclear yield, are eminently unacceptable. These consequences result in the most stringent requirements being applied to the safeguarding of direct-use SNM, and a series of less stringent or graded requirements for SNM that has to be converted to direct use. The spectra of perceived threats and presumed consequences vary with time. Changes in perceived threats are due to the technological advances made by adversaries and the changing utility of deterrents. Changes in presumed consequences are due to changing safeguards requirements resulting from reexamination of societal risk-acceptance criteria. Currently, for example, dispersal of SNM or other radioactive materials is included only by inference in the threat spectrum, being considered explicitly only as it results from sabotage of nuclear facilities. Inclusion of the dispersal threat, with candidate targets resulting from the use. of a corresponding societal risk-acceptance criterion, would alter safeguards requirements accordingly. In addition, if the socjal and economic impact of serisl, multiple, successful diversion attempts were to be considered, a decision to strengthen safeguards requirements might result. An early repeat of the accident that occurred at the Three Mile Island-2 reactor probably would have a greater adverse effect on the nuclear industry, because of the public perception of unsafe operations, than the sum of effects of individual events. A similar nonconstant weighting factor would be expected for multiple successful diversions of SNM.

Improvements in the capabilities of potential adversaries can be expected to follow, with little delay, the legal advancements made in our society. Proper credit must be given to the intelligence and ingenuity of adversaries and the substantial resources at their disposal. One must concede that, in 
many cases, the capabilities of adversaries represent a significant challenge to even ideal safeguards measures and protective forces.

\section{Motivation far Methodology Development}

The need for effectiveness evaluation methodologies for safeguards syatems began receiving serious consideration, not as a logical extension of the requirements stated earlier, but in reaction to the commencement of large-scale acts of international terrorism, the single most significant event being the storming of the Israeli athletes' compound at the 1972 Olympics in Munich. This and similar actions were carried out by well-armed and well-trained terrorist groups that acted overtly in overpowering physical security systems. These actions caused the nuclear community to be concerned about the adequacy of physical security systems at existing nuclear fuel-cycle facilities to counter such adversary threats. This concern induced several agencies--and several divisions within some agencies--to fund the development of a series of effectiveness models for physical security systems.

MC\&A functions were largely ignored because the nature of the suspected threat precluded their usefulness. However, recent examinations of personnel clearance programs used in the nuclear community show that the rejection rate for clearance requests is so small that one can conclude that clearance programs do not provide a significant deterrent unless one accepts the premise that the mere existence of the program discourages requests from potential adversaries. This premise seems unsupportable when one considers the full spectrum of presumed adversary objectives and motivations. The possible existence of the insider adversary beceme apparent, and the effectiveness of the MC\&A measures in thwarting the insider threat began to receive attention. More recently, there has been considerable interest in examining the performance of material accountability systems to determine the diversion sensitivity of existing systems and the improvements to be expected by altering strategies.

The preceding bit of history partially explains the plethora of effectiveness evaluation methodologies. Differing perceptions of the funding agencies and the methodology developers result in a sizable assortment of methodologies. Another factor contributing to the size of the assortment is the difficulty in developing these methodologies and the consequent expansion of the pool of developers.

\section{E. Methodology Development Difficulties}

One of the principal reasons why it is difficult to evaluate the adequacy of a safeguards system stems from the subjective or unknown performance features of most safeguards system components, including the unpredictable nature of the adversary's actions against which the system must perform. For a threat that involves only external adversaries, the emphasis in the safeguards system is placed on the physical security subsystem with some interplay from the material control elements. Evaluation of the physical security system usually involves examining the three functional characteristics of the system: detection, delay, and response. The interactions of these functions with a postulated adversary action sequence are difficult to determine 
simply because humans are involved. If the threat is expanded to include insider collusion with the external threat, system performance becomes difficult to establish, again because of the vast range of possibilities of insider assistance. If the threat is restricted to an insider, or insiders acting in collusion, the real-time safeguarding against theft is provided principally by material. control and some of the elements of the physical security system. Again, the unpredictable behavior of the insider, or insiders, coupled with the subjective nature of the performance of the safeguards elemerits makes the evaluation of system performance a cifficult task. Material accountability may indicate that theft or diversion of SNM occurred, however, the lack of timeliness of this safeguards element is generally not consistent with a policy of ensuring that SNM be restricted to the facility proper.

\section{F. Methodology User Requirements}

The responsibilities to reach a decision concerning safeguards sytems siffectiveness vary. The major burden for assurance of effectiveness should be borne by the facility operator. Indeed, the responsbility for such assurance rests with the facility operator. Familiarity with the details of the physical plant and its environs, intimate and real-time knowledge of the process and operations of the facility, and continued surveillance of the personnel and procedures suit the operator well for this task. The field offices and headquarters should assume the responsibility for reviewing the facility operator's efforts to evaluate the effectiveness.

By the very nature of a review, confirmation or verification, the detail required is less than that reasonably expected in the operator's evaluation. To distinguish these different levels of detail, we will use the words microscopic or macroscopic. Microscopic refers to the detailed diversion path surveys or analyses that require a minute examination of facility peculiarities, whereas macroscopic refers to more generic examinations that could be made on the basis of design information questionnaires, license submittal documents, and safeguards and security plans.

\section{REVIEW PROCEDURES}

Three previous reviews of effectiveness evaluation methodologies for domestic safeguards systems were conducted, two by R\&D Associates ${ }^{2}, 3$ (RDA), the third appearing as a review article in the Journal of the Institute of Nuclear Materials Management, Winter 1979-1980 issue." The first of the RDA reviews was available at the beginning of our study; the second one became available in draft form in December 1979, at the end of our review, There were few methodologies available at the time of the first RDA review; the second RDA review covers only evaluation methods for physical protection.

We reviewed the available methodology documentation and discussed it with the developers and the funding agencies. We also explored evaluation philosophies with them and with some individuals who were involved in making assessments of safeguards systems effectiveness. We base the conclusions and recommendations in this report on these interactions, with the intention of recommending the use of existing methodologies, if suitable. On this last point, it became clear early in our review that a great deal of effort has been 
spent on methodology development, whereas an inordlnately small amount of effort has been devoted to using the methods that are developed. This situation reaults from the differlng perceptions of effectlveness evaluation among funding agencies, which we remarked on earller. Specifically, the perceptions of individuals within those agencies who are responsible for awardling the development contracts differ; moreover, the perception persistence time and sometlmes even the tenure of these indivjduals are of shorter duration than the time required for completion of development. There has also been a tendency for the developers to work according to thelr own perceptions, whlch usually differ from those of the contracting organization, resulting in products that are considered defective by the contractors. Because this appears to be the prevailing situation, we suggest refraining from further method development, if at all possible, and instead recommend adaptations to existing methodologies as requirements or preceptlons change. Of course, for those safeguards measures for which no effectiveness evaluatlon methodology exists, we recommend development of such.

Our impressions of the reasons for the limited use made of these methodologles result from two basic objections: a general feeling among the licensing and regulating agencies that the methodologies are defective, resulting in a lack of guidance and direction for use, and a realization on the part of potential users that the application of such methodologies is resource intensive. Concerning the first objection, we recommend forgoing the search for perfection or completeness in methodologies in exchange for a commitment to the best among the defective. Indeed, the best among the defective will require the allocation of significant resources, an impact that users must prepare for if effectiveness evaluations are required.

In Sec. III we recommend a set of methodologies, albeit a patchwork of sundry items developed for disparate objectives that falls somewhat short of complete coverage. For example, interagency and intergovernmental agreements have never been subjected to formalized effectiveness evaluations and no methodology exists. Although an effectiveness evaluation methodology for transportation safeguards exists, we exclude it from consideration in this review. A measure that is relied on, especially in the deterrence and response function, for which credit is not usually taken by safeguards and security organizations, is the gathering and analysis of intelligence information. To our knowledge, the effectiveness of an intelligence gathering and analysis network has not been subjected to evaluations in the safeguards context. We deem these aspects of minor importance, perhaps presumptuously, and do not discuss them further in this report.

To discuss the effectiveness of deterrents in safeguards, one faces many difficulties. Deterrence measures may have nonexistent or even negative value on dedicated terrorists. Beres speculates ${ }^{5}$ that significant sanctions such as death penalties may even be stimulants to some terrorist groups. Legal sanction deterrents probably play a beneficial role in situations that reault from emploxee disatisfaction or otherwise peaceful demonstrations of the civil disobedience type. The efficacy of legal deterrents is largely unmeasurable because of the diverse nature and unknown characteristics of potential adversaries as well as the failure of the judicial system to hand down Indictments or to impose authorized penalties for violations of the Atomic Energy Act. The effectiveness of recovery methods is largely speculatlve and is likely to remain so, precluding analysis. We, therefore, limit our study to 
the methodologies for evaluating the effectiveness of fixed site safeguards ayotems.

Our conclusions and recommendations for a staged and stratified application of methodologies appear in Sec. III. Only limited input from field offices and facility operators was obtained for this study.

\section{CONCLUSIONS AND RECOMMENDATIONS}

We are aware of only two limited attempts to develop methodologies that evaluate all measures of most functions of a comprehensive system. These are Vulnerability of Integrated Safeguards Analysis (VISA) and Aggregated Systems Model (ASM), which are described in some detail in the appendixes. We feel that neither of these methodologies is suitable for use at the present time, because they fail to meet the criterion that the methodology be fully developed or nearly so. Effectiveness evaluations for comprehensive safeguards systems have such a wide scope that fully developed methodologies only address certain sections, with little or no effort spent on the remaining sections, as in the case of VISA, or else are uniformly incomplete, as in the case of ASM. Attempts to develop such comprehensive methodologies are laudable but, in our judgment, unnecessary because suitable methodologies exist for examining portions of the system. These various portions can be used coilectively to attempt a complete evaluation.

We offer the following general comments concerning the usefulness of the various methodologies we reviewed.

- Although the conclusions drawn concerning the effectiveness of a safeguards and security system may have questionable validity, the fact that the methodologies require users (be they system designers or system evaluators) to structure their thinking can have potential value in attaining an effective safeguards system.

- In our opinion, the effectiveness of safeguards and security systems is not quantifiable in such terms as "the system has a $95 \%$ probability of success againat the perceived threat." However, because authorized performance of material control can be quantified, and because material accountability is quantifiable, it -is possible to determine -the sensitivity of these system aspects to detecting diversion of SNM by an insider.

- Judgments about the effectiveness of a system are made by an individual or group of individuals; methodologies can aid in achieving sound judgment. This is true, of course, provided the individuals recognize the strengths and weaknesses of the methodologies used.

- To our knowledge, no validation exercises were applied to any of the methodologies, nor are there plans to conduct such exercises. We recommend that such exercises be done and suggest two possible approachess (a) select a methodology to examine criminal acts that were committed and ascertain if the methodology's results and the actual criminal results are the same and (b) analyze a safeguerds and security system for a nuclear facility with the methodology and compare the results with an independently conducted surrogate adversary operation. A combination of the two approaches might be worthwhile. 
We wish to emphasize that an evaluation of the vulnerability of a safeguards system at an operating facility needs to be staged. It is ludicrous to apply any of the formal methodologies prior to at least a perfunctory examination by expert assessors, an exercise designed to detect obvious deficiencies that must be resolved. All of these formal methodologies are manpower intensive; obvious irregularities should not be allowed to exhaust the allocated resources.

The following specific recommendations are grouped into two areas: physical protection (and material control) and material accountability (and control).

\section{A. Physical Protection and Material Control}

The purpose of the second RDA methodology assessment, mentioned in Sec. II, was to provide the Naval Surface Weapons Center with information on the availability and capability of computer-based techniques applicable to modeling physical security systems for shipboard nuclear weapons. In general, we agree with their findings and quote the report.

No single modeling system which is currently available provides all the capabilities that a security system planner or evaluater could profitably employ in a facility examination. A variety of complementary techniques are separately available; together, they can provide considerable insight into the adequacy of a physical security system.

For global evaluations* the RDA report concludes,

In the near future, the model of choice is probably SAFE**.... To provide a global examination of the security consequences of insider privileges, MAIT ${ }^{* *}$ is now the most useful model.

For scenario-oriented evaluations, the RDA findings for existing models state:

\footnotetext{
*RDA defines a global model as one that evaluates a security system systematically. It generates scenarios that are in some aspect especially threatening and then estimates the probability of attacker success in those optimized scenarios, identifying attacks to which the security system seems particularly vulnerable.

** SAFE is the acronym for the Safeguards Automated Facility Evaluation method, and MAIT for Matrix Analysis of the. Insider Threat. The reader who is unfamiliar with such specific methodologies should read the descriptions in the appendixes before continuing.
}

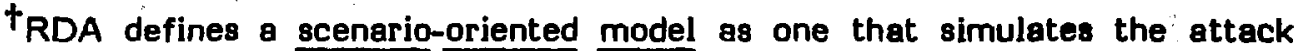
specified by the user in detail, tracing its progress and predicting its outcome. 
If a simple treatment is adequate, the EASI/BATLE ${ }^{*}$ combination is probably the best choice currently avallable.... SNAP* is the only modeling system currently available to carry out detailed scenario simulations.

Developers of most computer-based methodologies that address all elements of the physical security system--detection, delay, and response-presupposed that data bases could be made available to characterize the capabilities of each of these elements. In our opinion, only delay can be adequately characterized as a data base. To use this data base effectively, one has to assume the relevant attributes of the adversary, such as tools, explosives, mode of transportation, and weapons. Data bases for detection and response appear much more ambiguous. We question the value of incorporating these deta bases in the methodologies.

Of all the models RDA recommended for use, MAIT is the only deterministic one. We agree with RDA's recommendation. All of the others-SAFE, EASI/BATLE, and SNAP--require data that we believe is sufficiently subjective or unpredictable to question the evaluation capability of the codes as they now exist. SAFE includes the EASI/BATLE combination in evaluating the scenarios that the front-end of SAFE generates. SNAP also includes BATLE as its engagement model. The inputs required for SAFE, as well as for EASI, include probabilities of detection for sensors. In our opinion, reliable probability numbers are acquired by extensive testing of the particular sensor emplaced at the particular location in question; hence, care must be exercised in assigning such numbers. We were not able to obtain documentation for BATLE in time to ascertain its usefulness in general, though, we question the worth of sirnulating engagements and including such simulations in effectiveness evaluations. We would like to point out that the RDA assessment addressed only computer-based techniques.

With some small reservation, we appreciate the approach that the NRC followed in its past sssessments of fuel-cycle facilities. To evaluate the physical protection system, the NRC structured a graup of questions hierarchically, from subsystem performance to component performance, and provided specific guidance to the evaluators concerning the way to generate appropriate graded answers to the questions. These answers were then combined in a predetermined way through a methodology called Utility Theory in an attempt to provide a grade for the overall physical security system. The main reservation we have about this different kind of approach is the possible lack of completeness of the question set. It would take one or more well-planned exercises to demonstrate the validity of the results.

The NRC is in the process of generating a set of questions that can be applied to its recent upgrade rules and guidance. These questions specifically address a facility's capability to meet the new NRC regulations. This new

\footnotetext{
*EASI/BATLE is the acronym for Eatimate of Adversary Sequence Interruption/Brief Adversary Threat Loss Estimator, and SNAP for Safeguards Network Analysis Procedure.
} 
approach differs from the original quest ionnaire in that the questions were first generated and then structured from: the bottom up in an attempt to determine a grade for a facility (see Recommendation 4).

Another technique of which we are aware, but lack documentation, is the Sandia National Laboratories Generic Physical Protection Logic Tree (GPPLT)/EASI evaluation methodology, which is undergoing development. The Sandia methodology combines the GPPLT with a set of facility assessment questionnaires and standardized tests. This approach could have merit, provided EASI is treated properly.

With the foregoing comments in mind, we now provide specific recommendations for effectiveness evaluations of physical pratection and material control that can be performed today. Following these recommendetions for present methodologies, we make others for future development.

1. Recommendations for Applying Effectiveness Evaluations to Physical Protection 5ystems

a. For the system designer, the use of SAFE (with EASI input specified, as discussed earlier, and the results of the BATLE module carefully scrutinized) would be beneficial, provided access to the SAFE code can be achieved.* The end result of the application would be a determination of the guard force's capability to respond in time to interrupt the adversary sequence action. In the same way, the use of MAIT, if access to MAIT can be attained, ${ }^{\text {** }}$ would be useful, particularly when addressing the system vulnerability to the insider.

b. For operations office assessments and DOE/OSS oversight activities, no methodology exists for immediate implementation that would provide use ful results in the time frame usually allotted for such assessment activities. If assessments were made after the SAFE and MAIT applications, then review of the results would be useful. One recourse, at present, is to continue assessing the facility's ability to meet DOE orders. In our opinion, ensuring such a cepability does not necessarily imply that the system is effectives however, it does provide useful information for assessment pusposes. Another way to assess system effectiveness is to assemb?e teams in a manner comparable to that recently instituted in the DOE Site Security assessment approach.

\section{Recommendations for Future Activities}

B. As we stated earlier, we believe there should be no extensive new methodology developmerit in the near term and recommend that attention be

\footnotetext{
*Access to SAFE at the present time requires cooperation with Sandia. It is our understanding that the NRC has funded Sandia to make SAFE readily available to the NRC and licensees.

**Access to MAIT at the present time requires cooperation with the developer, Science Applications, Inc. (SAI).
} 
glven to validating exiating codes, particularly SAFE, MAIT, and the GPPLT/Queationnaire method now under development. Assuming validation is posslbie, the next activity should Involve identifying a way that the codes can be made readily available to potential use:s. The NRC currently has efforts to accompiish this and its experiences might be beneficial to OSS.

b. We believe that reliable evaluations of effectiveness will require experienced or knowledgeable people and we recommend that consideration be given to training people as evaluators. Such a training course should highlight the strengths and weaknesses of the cocjes and address the interpretation of the reaults. For example, the evaluators should realize that MAIT is a useful tool to help identify time-independent vulnerabilities in a system and that MAIT, although developed to analyze system vulnerabilities to insiders in collusion, can also be used to analyze system vulnerabilities to the external adversary.

c. The successful completion of Recommendation $2 a$ should provide guidance for identifying additional required evaluation methodologies or modifications of existing methodologies. In particular, keeping in perspective the needs of the users (facility operators, operations offices, and OSS) will help in identifying requirements for new methodologies.

d. In the NRC Nuclear Materials Safeguards and Security Division, the Regulatory Improvement Branch is funding Sandia to develop an evaluation methodology that assesses the capability of the physical security system at nuclear fuel-cycle facilities to meet the performance requirements of thie new NRC upgrade rules. We understand that a total of 100 different questionnaires, with an average of 13 questions each, were formulated and a methodology was developed that aggregates the snswers in such a way that subsystem performance and overall system performance can both be evaluated. A document that describes this methodology is presently undergoing review within the NRC. We recommend that OSS investigate the suitability of this method to help fulfill DOE needs.

e. A significant factor that affects the effectiveness of a physical security system is the capability of the response force, although this capability may be difficult to determine. We support the OSS effort to train the response force in appropriate tactics. This program will have an impact on improving the capability of the physical security system st a facility and may also identify needed research and development activities to enhance the response force's capabilities.

\section{B. Material Control and Accountability}

An initial concern in the evaluation of an MC\&A system is that of compliance with orders and regulations. A formalized method for making such an evaluation has been deveioped. It is the Safeguards Management Analytical Risk Tree (SMART) methodology, which is

...designed to set down, in a logical manner, factors which need consideration in maintaining a viable safeguards system. Each element of the analytic diagram is to be considered and a judgment 
rendered as to whether the element under consideration is adequate, less than adequate, or not applicable.

This logical analysis of the management system must be done, but such an evaluation does not require a formal methodology. The existence of the proper administrative policies and procedures is a necessary condition for an adequate MC\&A system, but performance measures must also be suitable. No further elaboration of the SMART methodology is contained in this report.

We recognize a broad spectrum of facility characteristics based on material quantitites and material traffic. Material accountability for interim storage vaults with little traffic across the material access area (MAA) boundary presents a different challenge than that encountered for highthroughput process lines with multiple material balance areas (MBAs). For all facilities subject to licensing or regulation, there are requirements for physical inventory taking and for reporting of the book-physical inventory difference (BPID). Interpreting the legitimacy of the reported BPID depends on the inspector's strategy for inventory verification and on the historical records, including previous BPIDs and process, procedural, or measurement alterations over the historical span. The effectiveness of the procedures used in inventory verification should be evaluated and optimal strategies developed. Baloga proposes providing uniform guidance for inventory verification. ${ }^{6}$ a method for evaluating the legitimacy of the reported BPID, based on historical data from the same facility, has been developed it is referred to as Measurement Control, LEMUF, and MUF ${ }^{* *}$ Simulation (MCLAMS).

Three parameters describe the performance of a material accountability systems loss-detection sensitivity, detection probability, and time required to achieve the stated sensitivity at the stated detection probability. The Los Alamos National Laboratory has developed methods for generating the performance surface--the continuous functions relating the three parameters-that incorporate the peculiarities of a given material accountability system, namely, the material process characteristics, the measuring instruments and associated uncertainties, and the measurement control program. It is also possible to construct performance surfaces of conceptual systems as well as those in operation. Using such methods, one can determine the capability for diversion detection and can conduct sensitivity studies for alterations in measuring equipment or strategies. Adversary strategies are not explicitly modeled, but the inherent capability of the system can be determined.

Evaluations of the MC\&A system vulnerabilities, using the diversion path analysis (DPA) methodology, assume adversary strategies of stealth and deceit. This is a microscopic, scenario-based methodology designed to determine the vulnerability of the system to such strategies used by knowledgeable insiders. The methodology assesses the ability of the MC\&A systems to detect, within specified times, the removal of a specified quantity of SNM from an authorized location, and it identifies diversion paths that are uncovered for which there is an inadequate response.

* Limit of error for material unaccounted for.
** Material unaccounted for. 
The DPA mathodology equates undetected removal from an authorized location with removal from the MAA with the further implied assumption that removal from the protected area (PA) is then inevitable. It is regrettable that the DPA methodology makes no evaluation of the physical protection measures that micht cover some diversion paths left uncovered by the MC\&A measures. We recommend the development of a suitably compatible counterpart to DPA that evaluates the effectiveness (by diversion path techniques) of thie physical protection system against attempts to remove SNM from an MAA using a stealth-and-deceit strategy.

We acknowledge that DPA-like methodologies are manpower intensive because they involve scenarjo building. At the same time, and because of the scenario-based riature, such methodologies can provide for a more nearly complete evaluation. Although scenarios constitute a countably infinite set and allow for the seemingly endless "what if...?" ratcheting game, the methodologies themselves are not inherently limited and can answer each of these questions in turn until a suitable completeness criterion is reached. A similar approach, less formalized than DPA, might use hierarchial questionnaires, which the NRC is considering for evaluating effectiveness of physical protection and MC\&A systems under its upgrade program. However, DPA enjoys the advantages of complete documentation and a history of implementation.

The nature of DPA is such that facility operation personnel are essential members of the evaluation team. This methodology provides the potential for a thorough examination of the facility, but at the same time precludes the overview function desired by the field office inspectorate. The detailed input requirements for DPA also make it less attractive for confirmatory purposes. However, the matrix manipulation methods, MAIT and the Safeguerds Vulnerability Analysis Program (SVAP) provide such capability and can be used even away from the facility under examination. MAIT has already been discussed in the section on evaluation methodologies for physical protection systems. SVAP closely resembles MAIT; however, SVAP includes a material accountability system. There is a cansiderably larger body of information and a usage history of MAIT. Development of SVAP has just been completed.

1. Recommended Activities Preparatory to Using MC\&A Evaluation Methodologies

a. A comprehensive guidance document for a uniform inventory verification strategy should be developed.

b. DPA should be modified to require only the minimum input information and data. Much of the information requested on DPA workstieets is superfluous and impacts inordinately on the facility operator's resources. This may be part of the difficulty in promoting the use of DPA in the past. As long as the operator personnel are pari of the DPA team and the effort involves a significant time in the facility, it. is likely that most of the required information and data can be obtained in less formal fashion.

\section{Recommendations for Use of These Methodologies}

a. Performance surfaces for material accountability systems should be generated using process, measurement, and measurement control simulations 
for determining the limit-of-error performances of existing MC\&A systems in key facillties. The Los Alamos programs* contain all of the key elements. MCLAMS* has no process modeling capability, but can be used to examine historlcal performance.

b. Assessments should be made by teams of experts that visit the facllties and use professional judgment to discover obvlous deficiencies or irregularities in extant systems.

c. DPA or its abbreviated form--Initial Diversion Vulnerability Assessment $\mathrm{t}^{7}$ (IDVA)--should be used for the microscopic evaluations. These tools appear to be such that changing requirements, such as dispersal threat addition, or expansion of the target material or quantlty sets, can be accommodated in a rather straight forward fashion.

d. Based on a reasonably complete facility description file, field offices should use MAITt as a macroscopic evaluation tool. Proposed facility changes, both physical and procedural, could be examined for effects on safeguards system performance. This recommendation presupposes the availability of reasonably detailed site plans and procedures for safeguards and security.

\section{Recommendations for Further Development}

a. A DPA-compatible mel:hodology should be developed for evaluating the effectiveriess of the physicsl protection measures against the threat of SNM removal, by stealth or deceit strategies, by a knowledgeable insider.

b. Facility safeguards and security plans, in a MAIT-compatible format, should be formulated to provide an extensive data base for periodic examination of facilities by field offices. A suitable repository for this data base should be provided in the appropriate field offices.

* Transferability or transportability of these codes is being addressed. Sample codes are being used at the Joint Research Center, Ispra, Italy, and will be used at Allied General Nuclear Sciences (AGNS). This particular step in the evaluation process perhaps is best left to be done by Los Alamos at the present time.

**MCLAMS is a computer code based on a Monte Carlo algorithm. Consequently, the computer coire requirements are moderate. Transferability of the codes is possible. Initial development was done by SAl; the NRC now possesses replica codes for in-house work.

${ }^{+}$A computer is not required for the basic DPA or IDVA vulnerability assessment. However, convenient cross-reference sets are provided by computer. This could continue to be done by the National Bureau of Standards (NBS).

HAccess to MAIT at the present time requires cooperation with SAl, its developer. 


\section{EASI (ESTIMATE OF ADVERSARY SEQUENCE INTERRUPTION)}

EASI is a methodology developed by Sandia and sponsored by the NRC. It addresses the probabillty of the physical protection system responding in time to interrupt sperific adversary action sequences. EASI is well documented? and is perhaps the most widely used evaluation tool. To quate from the abstract of Ref. 7:

A simple, essy to use method, called Estimate of Adversary Sequence Interruption (EASI), has been developed to evaluate physical security system performance under specified conditions of threat and system operation. The method consists of a probabilistic analysis of the interactions of basic security functions, such as detection, communications, response, etc. The evaluation can be performed on a hand-held programmable calculator.

There are two reasons why EASI eppears to be the most widely used tool to evaluate the effectiveness of a physical security system: (a) it is simple to use in the field and (b) it received exposure from its inclusion in the Workshops on Physical Security that Sandia conducted.

The EASI method requires the following data:

- detecíion probability for each sensor, or other means of detection, and the location of the sensors in the sequence of adversary actions;

- probability of communication to initiate a response;

- the mean and standard deviation of the response time; and

- the mean and standard deviations of the times to perform each task in the adversary sequence.

Given the input, the EASI method analytically calculates the probability of sequence interruption for the particular scenario specified. To address a second scenario, new data reflecting the new scenario must be used.

The subjective nature of portions of the input data makes the output from EASI subjective. However, EASI does provide a structured, inexpensive, and easy way to gain insight into the characteristics of a physical security system. Such insight might be useful in identifying significant vulnerabilities.

It should be noted that EASI does not contain any engagement scenarios. To quote the developers of EASI, "Forceful neutralization involves human interactions which are extremely difficult to represent correctiy in simple terms (and may be difficult in any terms)."1" EASI simply addresses the question: given the adversary actions and the characteristics of the physical security system to oppose the actions, what is the probability that the actions will be interrupted? 


\section{BATLE (BRIEF ADVERSARY THREAT LOSS ESTIMATOR)}

BATLE $^{\theta}$ is an analytical model--developed by Sandia for the NRC--that can be used to simulate small unit engagements. An engagement scenario is bullt by describlng individual combatants and site-specific characteristics for the series of events that comprise the engagement. The model uses self-contained data currently based on military experience to determine the attrition rates for both sides. The attrition rates are then used in a mathematical model (a modified Markov process) to determine the number of combatants remaining at the end of the engagement, the duration of the engagement, and the probahility of either side wlnning the engagement.

The model is conceptually straightforward and is quite easy to use. BATLE allows the user to quickly modify a scenario to investigate the effect of changing the characteristics of the engagement. Therefore, the model can be used in analyzing a particular situation or in developing future security force configurations.

\section{FESEM (FORCIBLE ENTRY SAFEGUARDS EFFECTIVENESS MODEL)}

FESEM is a Sandia-developed, NRC-sponsored computer simulation model that addresses the effectiveness of the physical security system of a facility against forcible attack by outsiders. The code-is well documented and a User's Manual exists. ${ }^{9}$ To quote from the introduction of the User's Manual:

FESEM is a combined (discrete and continuous) cornputer model for analyzing fixed-site security systems as to their effectiveness against a forcible attack by an adversary intent on creating an act of sabotage or theft. The model applies Monte Carlo simulation to problems of forcible entry, for any assumed physical path, by an adversary having a variety of attributes and gives an estimate of adversary success probability. The model includes variables related to detection, assessment, communication, delay, and neutralization. Output statistics on various aspects of each scenario are provided by the model and may be utilized by the decision makers as an aid in evaluating or upgrading a physical protection system.

Data used by the FESEM code include the physical characteristics of the assumed path: barrier penetration times, chosen randomly from a triangular distribution function with the user specifying the minimum, mode, and maximum values; detection capability, chosen randomly from a uniform distribution with the user specifying the detection probability; and the distances between the locations of the barriers and detectors, likewise specifjed by the user. The user also specifies the probability of successfully communicating a detection to the response force as well as the response force characteristics, given by the numbers arriving, the arrival time specifications (again, chosen randomly from a triangular distribution identified by a minimum, mude, and maximum), and their dedication. Adversary characteristics include mode of travel (foot, land vehicle, or air vehicle, which affects the travel time between various barriers and detection elements), number, dedication, and equipment. Included in FESEM is an engagement simulation that essentially is described by a coupled set of differential equations with varying coefficients. One equation pertains to the response force; the other 
pertains to the adversary. The coupling between the equations occurs through the coefficients that address the casualties, including quit rates, and that depend in part on the number of the opposing force, which in turn depends on successful detection of the adversary.

For a given set of input specifications, the simulation of the adversary attack and the response force actions is repeated a number of times. The output (the adversary succeeds or does not) varies, depending on the particular values randomly chosen from the various distributions. From these repeated simulations, information is generated concerning the probability for adversary success (or conversely, the probability for response force success), the average time associated with the adversary success or defeat, the. number of remaining forces, and so forth. If the user wants to examine another scenario, the appropriate input has to be modified to reflect the characteristics of the new scenario.

FESEM includes, in essence, all aspects of a physical security systern detect, delay, respond, and neutralize. As with most simulation models, the output is always open to question because of the subjective nature of the input data. Likewise, the appropriateness of the engagement model is also open to question.

\section{SAFE (SAFEGUARDS AUTOMATED FACILITY EVALUATION METHODOLOGY)}

SAFE is a Sandia-developed, NRC-sponsored methodology for evaluating the effectiveness of the physical security aspects of a safeguards system. SAFE consists of a collection of functional modules for facility representation, component selection, adversary path analysis, and effectiveness evaluation. The technique has been implemented on an interactive computer time-sharing system and makes use of computer graphics for the processing and presentation of information. ${ }^{8,10}$

Program input consists of facility layout characteristics, which become a computer representation of the facility. Then the analyst has to specify component performance for individual safeguards elements. The generation of adversary scenarlos (sabotage or theft) is achieved next by selecting optimal paths through the facility for the adversary. SAFE uses one of three measures for adversary path finding: (a) minimum adversary task time, (b) minimum adversary detection probability, or (c) minimum timely detection of the adversary, or those paths that minimize the probabllity that the security force can confront or interrupt the adversary. Finally, the effectiveness evaluation associated with these paths is analytically determined: EASI is used to determine the probability of adversary interruption and BATLE is used to determine the probability of adversary neutralization. The product of these two probabilities yields a measure of the probability of successfully defeating the adversary. SAFE is advertized as a global evaluation tool inasmuch as it considers the whole facility and determines specific paths appropriate for a specific set of measures.

SAFE was used to evaluate the design of a physical protection system for the Consolidated Fuel Reprocessing Program's Hot Experimental Facility. ${ }^{11}$ To quote from the reference: 
The most versatile evaluation tool we have examined for use during the early conceptual design has been SAFE.... The computer graphics capability of SAFE that allows the analyst quick and yet detailed assessment of some basic features of the facility design that are subject to change or redesign makes this tool worthwhile even when the architectural features of the facility are still uncertain....

The establishment of a data base to use with SAFE was identified in Ref. 11 as a difficult task to accomplish. Because SAFE employs EASI and BA.TLE, the output is subjective and must be scrutinized carefully by an an iyst. SAFE has application in sabotage studies of light-water reactors. The NRC is considering SAFE for just that application.

SAFE has been developer to be user efficient. It is essentially an automated evaluation tool.

\section{SNAP (SAFEGUARDS NETWORK ANALYSIS PROCEDURE)}

SNAP is an NRC-sponsored methodology, developed by Prisker and Associates, Inc., through subcontract to Sandia, for evaluating the effectiveness of the physical security measures of a safeguards system. ${ }^{12}$

SNAP employs the network modeling approach to problem solving. By combining the SNAP symbology with knowledge of the system, specific scenarios, and modeling objectives, a network model of the system, may be developed. SNAP provides a structure for safeguards systems analysis by dividing safeguards systems into three interacting submodels: (a) the facility submodel that is concerned with the physical characteristics of the facility itself, (b) the guard submodel that involves guard operating policies and includes a representation of the decision logic associated with guard forces as well as the physical movement of guards through the facility, and (c) the adversary submodel that involves the decision logic and sequence of events that an adversary must complete to reach a certain target.

With SNAP, the focus is on micro-completeness, ${ }^{*}$ and the analyst is afforded the flexibility to model individual scenarios to virtually any level of detail that is deemed appropriate. ${ }^{13}$ The SNAP methodology employs Monte Carlo techniques to simulate randomness in the specific scenarios that are being evaluated. SNAP requires explicit user input to represent the tactical processes employed by the guards and the adversary. The engagement model used in SNAP is BATLE, ${ }^{14}$

SNAP is a simulation language developed specifically for modeling safeguards systems. With the SNAP approach, the analyst constructs a model of the safeguards system by interconnecting a set of SNAP symbols to represent the system elements and their interactions. The resulting SNAP networks are

\footnotetext{
* A micro-complete methodology is defined as one in which safeguards effectiveness is eyaluated for each scenario in sufficient detail to adequately represent all relevant considerations.
} 
then transferred to a computer-compatible form by data cards representing the symbols and their interconnections.

Because SNAP is highly scenario dependent, the analyst can examine tactics employed by guards for each adversary tactic assumed. The Monte Carlo nature of SNAP allows a given scenario to be repeated many times to produce an eatimate of the system performance in dealing with the specific scenario defined.

The input data required for SNAP (facility characterization, such as probabilities of detection, delay times, and the use of engagement models) imply that the results obtained are subjective. The analyst has to rely on his judgment In interpreting the results from SNAP. Nevertheless, SNAP might be a useful tool to investigate tactics employed by guard forces in response to adversary actions.

\section{SSPAM (SECURITY SYSTEM PERFORMANCE ANALYSIS METHODOLOGY)}

SSPAM is a DNA-sponsored methodology, developed by Mission Research Corporation, that evaluates the physical security system aspects of a safeguarjs system, SSPAM is still under development; however, its concept has been documented. "is

SSPAM appears to be one of the more ambitious undertakings to develop an evaluation tool for physical security systems. The approach is to produce a modular code in which each module can be omitted from the evaluation or replaced if a better module is developed. The extremely detailed approach includes all elements that affect the effectiveness of a physical security system, even though they may be extremely subjective in nature, such as sensor performance, barrier performance, guard/adversary interaction, and effects of terrain and weather.

The justification for developing SSPAM apparently resulted from a literature search from which it was concluded: "No literature was found that deals specifically with performance assessment methods for physical security systems at nuclear weapon storage sites. its

A skeletal version of SSPAM is available. Approximately two more years will be required (at a 3-man-year/year level of effort) to complete SSPAM.

As with most evaluation methods that address the effectiveness of a physical security system, the subjective nature of the input data required for SSPAM yields results that have to be interpreted by the analysts.

\section{UTILITY THEORY}

A methodology that uses utility theory was developed by Sandia for the NRC. As part of the appraisal of their fuel-cycle facilities, the NRC establiahed a set of approximately 70 questions that addressed, in a hierarchical manner, the essential elements of a physical security system. Evaluators, instructed to answer each question, assigned a numerical value 
(1 to 5) to each of the questions. As an after-the-fact involvement, the NRC asked Sandia to provide a means of aggregating these ratings to measure the adequacy of the physical security system. The resulting method is referred to as the utility theory approach. ${ }^{16}$

There are four levels in the hierarchical structure that the NRC developed at which criteria rating are suggested. The overall rating of the system depends on the values assigned to the question, which constitute the lowest level of the heirarchy. An attempt was made to reduce the subjective nature of the answers to the questions; however, subjectivity does remain.

One wonders whether the questions that were formulated were the correct questions. An evaluator does, however, have guidance to examine specific aspects of the physical security system by asking such questions.

The utility theory approach to evaluation is global in nature. This approach does not consider specific scenarios; instead it considers the elements of the safeguards system and examines their integration.

\section{VISA (VULNERABILITY OF INTEGRATED SAFEGUARDS ANALYSIS)}

VISA is an NRC-sponsored methodology, developed by SAl, which evaluates the performance of a riuclear facility safeguards system for defeating attempts of theft or sabotage. The general framework or structure of the VISA evaluation methnd is fairly well defined and documented. 17,18 Because VISA is a concept that has not been developed to the point of full implementation, it has not been applied to evaluate any safeguards system. The VISA concept principally addresses the physical security aspects of the sefeguards system (detection, delay, response), but can address material control to a certain extent. It does not, however, address material accountability, so in a sense, the "integrated safeguards analysis" refers to an integrated physical security system and not a fully integrated safeguards system that would also include material accountability.

As with most evaluation models for physical security systems, VISA is based on the assumption that performance data concerning individual safeguards elements either exist or can be obtained. Two data bases that are assumed to exist are (a) a detection mechanism data base and (b) a delay mechanism and engagement data base. VISA is an analytical method for combining these performance data for individual elements into an overall figure of merit. An adversary action sequence has to be identified by the user; this sequence is paired against the safeguards elements that can interact with the sequence. A detection probability $\mathrm{PD}_{\mathrm{D}}$ is calculated for the system capability to detect covert adversary actions for the specifjed path. An analysis is performed to determine the outcome of overt adversary actions, and a figure of merit $\mathrm{PC}_{\mathrm{C}}$ is derived for the system capability to defeat the overt adversary actions and contain material within the facility. A final analysis combines the results from $P_{D}$ and $P_{C}$ to determine an overall figure of merit for the system capability to prevent an adversary from achieving his objective--theft or sabotage. The nature of the assumed data bases plus the subjective nature of the engagement model requires that the results be treated subjectively. 
ISEM is a DOE-sponsored, Sandia-developed methodology that addresses the effectiveness of a safeguards system to counter an adversary who has authorized access to a facility. ISEM was one of the earlier developed methodologies and is adequately documented. 19,20

ISEM employs Monte Carlo techniques to simulate a group of insiders attempting to steal SNM or sabotage the facility. In effect, ISEM examines the personnel control system (portals, guards, and sensors) to ascertain the effectiveness of the system to successfully defeat a specific adversary scenario. Input to the code requires the facility layout, the sensor and portal detection capabilities, and the guard force tactics employed in responding to an alarm. The confrontations between guards and adversaries are modeled as discrete-state continuous-time stochastic processes. ${ }^{21}$ The states are the number of combatants actively involved in the confrontation; transition times between states are assumed to be continuous random variables that are a function of the force size, weapons, and competence of the opposing forces.

Several replications of a specific scenario are run to determine the effectiveness of the system to defeat the insider activity. Neither material accountability nor material control is considered.

For the most part, the input data required for ISEM are subjective in nature. Thus, the results have to be interpreted by an analyst.

\section{MAIT (MATRIX ANALYSIS OF THE INSIDER THREAT)}

MAIT was developed by SAI for the NRC. The methodology is adequately documented. ${ }^{22-25}$ MAIT allows the facility safeguards analyst to systematically evaluate the vulnerabilities of a facility safeguards system to collusion among facility insiders. The methodology is quite general in that the cases analyzed are only limited by the user input parameters. As currently used, the methodology evaluates all insiders and any outsiders of concern, either acting alone or as pairs in every combination. MAIT covers plant parameters such as location adjacencies, safeguards locations, persannel groupings, facility conditions, and adversary threats by placing these parameters into computer matrices. From this data base the computer generates every possible path for all threats. In addition, guidance is presented on methods for developing work rules to reduce the threat from colluding insiders. MAIT has been used for evaluation of theft and sabotage threats at nuclear fuel processing facilities. However, it is sufficiently general to be used in other facilities for evaluating resistance to other postulated threats.

The methodology has three main portions: facility modeling, analysis, and assessment. The objective of the facility modeling portion is to convert information gained from facility physical security plans, site visits, and personnel interviews into data input for the computer. This is done in two major steps. The first step is the collection of data regarding the adjacencies of real locations in the facility. The second step involves collection of data for each safeguards component in the facility. Another important input is the 
opecification of the adversary start position, the target position, and the adversary final position.

The computer analysis portion of MAIT is a complex series of nested loops that analyzes every possible combination of path, threat, condition, and pair of colluders. The computer output is in three general categories: input playback, summary output, and detailed output. Input playback shows all the data that have been entered into the computer for the locations, safeguards components, personnel, threats, and conditions. The information is formatted to be of use to the analyst in ascertaining that it is a correct reflection of the facility under analysis. The summary output presents a statistical picture of the effectiveness of the facility safeguards against colludiuly insiders. Statistics are presented on the number of sequences that had $n$ remaining safeguards components and their relative percentage. Summary information is presented on targets, personnel pairs, threats, and facility conditions.

For the assessment portion, the analyst calls up a detailed output for a specific sequence of concern that was shown to be critical by the summary output. This output shows the actual sequence of locations that defines the path, the safeguards vector, and the safeguards components that do not apply because of the threat. It also provides the key information concerning the safeguards components that were compromised by the pair of insiders and details how they overcame each cne they defeated. When the data for all critical sequences are available, the analyst may begin a program of safeguards system enhancements to effectively interpose additional safeguards components. These enhancements may include the removal of authorizations for critical personnel pairs for those safeguards components that were defeated during the pairs' critical sequences, 


\section{APPENDIX B}

\section{EVALUATION METHODOLOGIES FOR MATERIAL CONTROL AND ACCOUNTABILITYY}

\section{DPA (DIVERSION PATH ANALYSIS)}

DPA is a completely documented methodology ${ }^{26}$ developed by the NBS for the DOE. DPA is useful for determining the vulnerability of MC\&A measures to the threat of diversion of a specifjed quantity of SNM, within a specified time, by an insider using a strategy of stealth and deceit. Diversion is presumed to have occurred if the SNM is removed from its authorized location within operational arees-it need at be taken from the area. Theft of SNM is the objective; sabotage is not addressed. S!upervisory personnel are excluded from the adversary list, not because there is a priori assiurance of their lack of intent to divert, but because diversion by such personnel, using their authorizations, is always possible in the short term, obviating the need for including them in the evaluation.

Currently, the target material set includes ${ }^{233} \mathrm{U},{ }^{235} \mathrm{U}$, and ${ }^{239} \mathrm{Pu}$, with the target quantity being $500 \mathrm{~g}$ of plutonium or ${ }^{233} \mathrm{U}$ and $1500 \mathrm{~g}$ of ${ }^{235} \mathrm{U}$ and a time to elude detection of $24 \mathrm{~h}$. These are guidance values and can be changed without affecting the methodology. Consistent with the concept of graded safeguards, an attractiveness factor is assigned, based on the physical and chemical description of the $S \mathrm{NM}$, and the radiation hazard attendant to handling it. Subjective judgment underlies the assignment of these values.

DPA considers two types of insider adversaries: embezzler and thief. The thief lacks one or more of the authorizations enjoyed by the embezzler: access to the operational area, access to the records, authority to handle the SNM, and authority to make entries to the records. Choices include leaving the records unchanged, altering them or falsifying them, and possibly substituting dummy material for that removed. A set of 16 general diversion paths (GDPs) are identified involving these possible actions and one or two adversaries. Subjective judgment has been used to assign a weighting factor to each of the possible actions involved in a given diversion path, resulting in a nonconstant weighting factor (the relative path weight) for the GDPs. The weighted GDP value is maltiplied by the SNM attractiveness factor and the radiation hazard factor to yield a value called the adjusted relative path weight.

DPA consists of five basic steps: information and data gathering, process characterization, analysis of diversion paths, results and findings, and documentation. The first two steps receive more attention than is warranted. The recommended information worksheets call for data and information that are not used, apparently, in the later steps. A large portion of the information requested seems to be used for orientation of the DPA team rather than in syntheses of the process areas. Because the team makeup includes personnel from the facility who are familiar with the process, safeguards components, and procedures within the facility, much of this information and data are superfluous. 
The third step, analysis of diversion paths, is accomplished according to the flowchart in Fig. B-1. This step uses worksheets (Fig. B-2) that are solely for the purpose of making a written record of the real actions involved in a diversion path analysis, namely, the generation of scenarios suitable for SNM removal. The DPA team members are required to assume the roles of adversaries in the analysis of the GDPs. The worksheets guide the team members through the thought processes necessary to analyze the diversion paths and to produce the ancillary data concerning potential observers and possible causes for abnormal situations other than the SNM diversion.

It is only after analysis of the diversion paths step is completed that computer assistance is used. Several computer-generated tables are available. These include cross-referenced sets for abnormal situation number versus specific diversion path number, detection time versus specific diversion path number, potential observer versus abnornal situation number, and potential observer versus specific diversion path numbers. These crossreferenced sets will be used to determine modifications that will improve the response capability of the MC\&A subsystems and reduce the detection time for the discovered vulnerabilities. The proposed modifications can be incorporated for a rerun of the cross-referencing collation routine.

DPA does not examine the material accountability subsystem to determine its capabilities. It is designed only to discover vulnerabilities to a specified threat of the MC\&A subsysterns considered independently of the physical protection measures.

DPA has been used for evaluations at several facilities. The manpower requirements may be estimated from the effort spent on evaluating part of the $32 \mathrm{IM}$ building and process at the Savannah River Plant. That effort required 2 man-years of effort (at a rate of 2 man-years/year) with a technical personnel mix including one professional staff member, one process technician, and one data processing specialist. Reference 27 provides a complete description of this application at Savannah River, which was deemed helpful for evaluating and improving the internal control safeguards at the facility.

\section{IDVA (INITIAL DIVEF SION VULNERABILITY ASSESSMENT)}

The NBS developed IDVA ${ }^{28}$ out of DPA for the DOE. To reduce the manpower requirements associated with a diversion path survey, an abbreviated form of DPA was produced, essentially by truncating the general diversion path list of DPA. IDVA considers only those GDPs with a relative weight of 0.5 or greater. The resulting list contains 7 GDPs out of the 16 addressed in DPA.

\section{MCLAMS (MEASUREMENT CONTROL, LEMUF, AND MUF SIMULATION)}

MCLAMS ${ }^{29,30}$ is a computer code based on a Monte Carlo algorithm developed by SAI for the NRC. MCLAMS simulates the performance of SNM accounting. It provides the capability to

- calculate the accuracy of a measured SNM balance; 


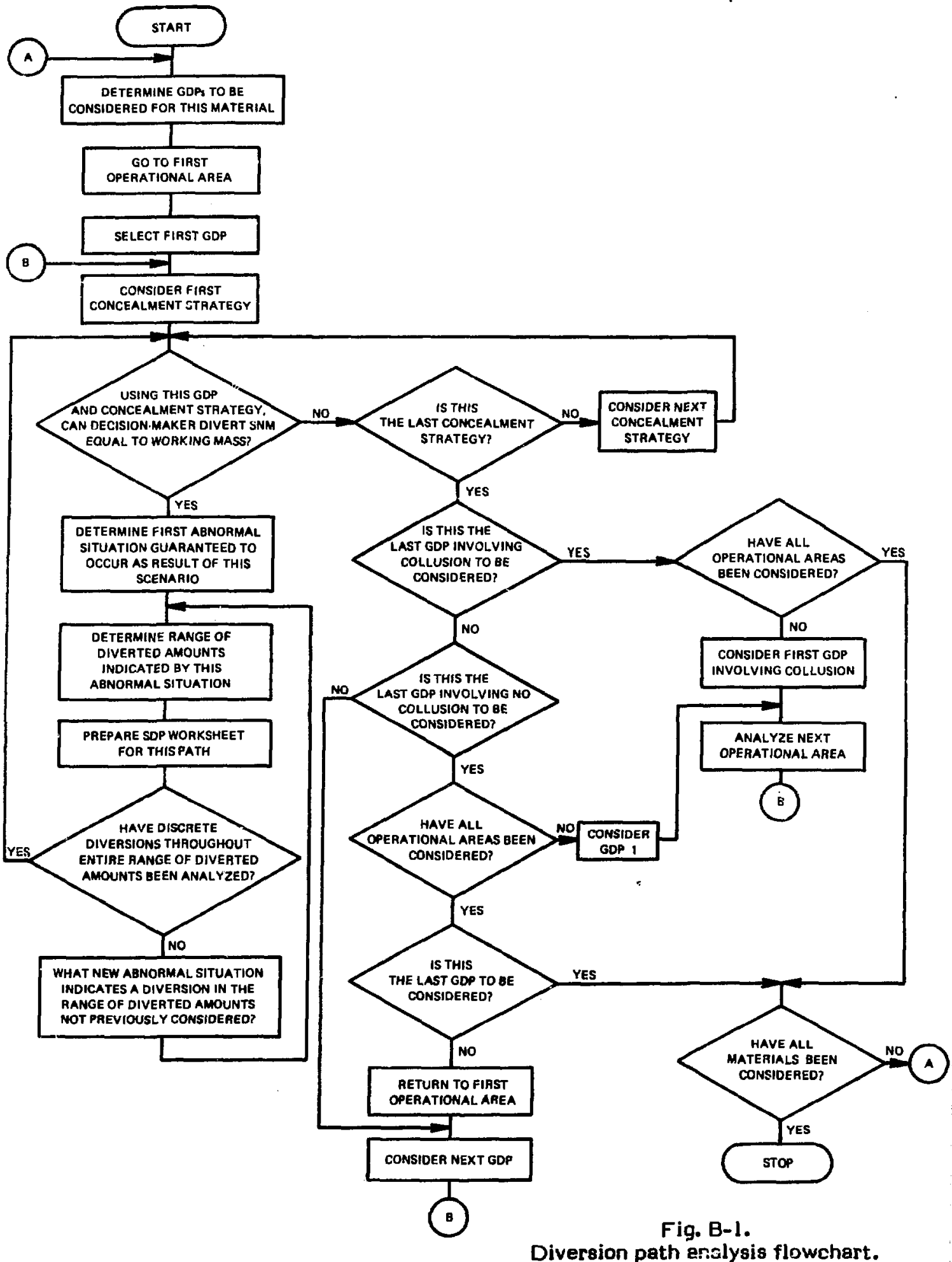

Diversion path enslysis flowchart. 


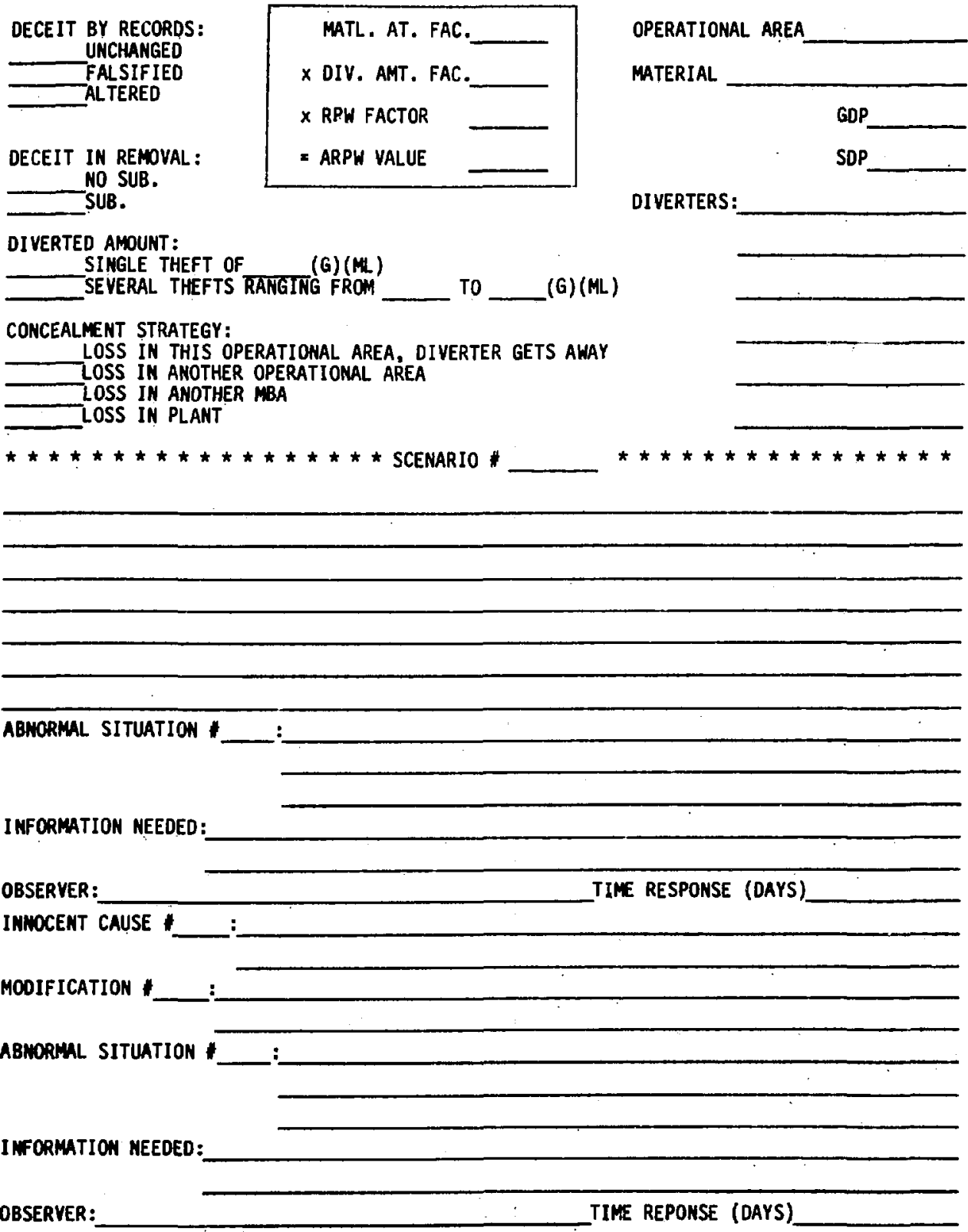

Fig. B-2.

Specific diversion path worksheet. 
- simulate individual measurement error data and the resulting material balance accuracy data for different measurement control plans;

- simulate the MUF data that includes measurement error, process losses or gains, and possible diversion; and

- compute alarm rates by comparing the MUF data with an alarm threshold that is a multiple of the measurement error.

MCLAMS can be used in making decisions about acceptable values for alarm thresholds and in diagnosing whether past alarms are meaningful or should be interpreted as false alarms. Simulated results can predict future performance of material accountability systems.

The modeling is limited to the material accountability system and does not depend on any particular type of nuclear processing activity; however, it is generally applicable to all nuclear operations. Although it is the error structure of the measurement program that is primarily modeled, one necessary input to the model is the amount of each form of SNM on inventory or being transferred past measurement points.

The MCLAMS model (Fig. B-3) has four sources of input: the average errors for the measurement methods; the frequency of measuring standards for the measurement control program; the material flow and inventory quantities, including average number of measurements (weighings, samples, and analyses) per batch; and distribution parameters describing process loss/gain mechanisms. Theft simulation is treated as a special case of the process loss/gain mechanism. The structure of the material accountability system consists of analysis of variance methods for determining the measurement errors from the simulated measurement control data, the limit of error in the MUF calculation model, the MUF simulation model, and the MUF/LEMUF hypothesis test.

The average error for the measurement method refers to the relative standard deviation of the distribution of measurements performed by a given measurement method. In general, it may be the industry-wide average, the state-of-the-art performance, results of special testing programs, or other plant-specific measures of measurement capability. The frequency of measuring standards is in terms of the number of measurements of standards per calibration period and the number of replicate analyses used to estimate sampling variances. The material flow and inventory data include the quantity of material per batch, the number of batches per calibration period, the number of calibrations, and the number of weighings, samples, and analyses performed on a batch. The sources of the other input data--the process loss/gain data--may not be readily available. As a starting point, one can assume that there are no process loss/gain mechanisms. Examples of the types of mechanisms that could then be modeled are unmeasured residues in equiprnent and ventilation ducts, and effluents such as waste water. The measurement control simulation model generates random numbers that simulate the results of measuring standards and repeating measurements. Measurement errors are modeled as one of the following types:

- random errors that affect each measurement differently, 


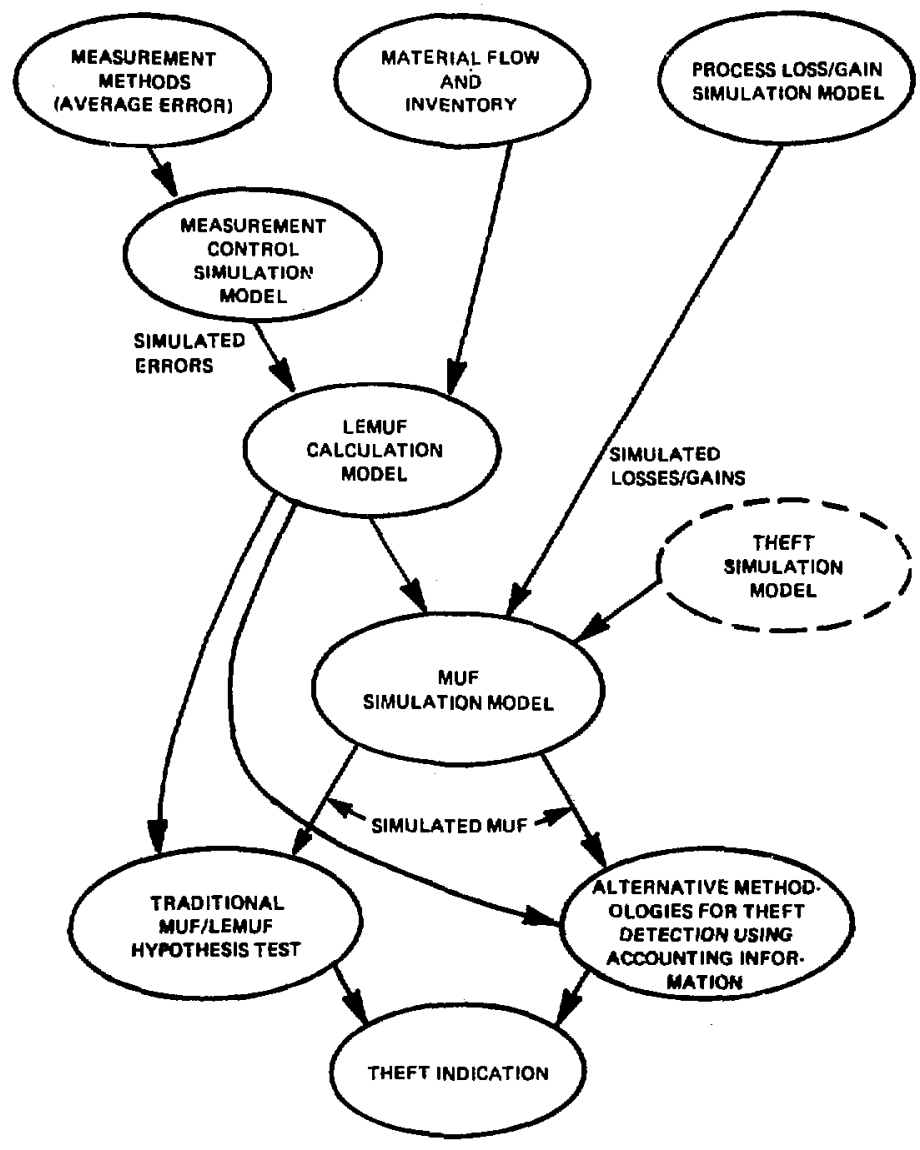

Fig. B-3.

Schematic of the MCLAMS code. 
- short-term systematic errors that affect a.group of mea:surements (for example, within one calibration) in a constant way, and

constant way.

bias or systematic errors that affect all measurements in a

The simulated errors from the measurement control simulation model are combined with the material flow and inventory quantities in the LEMUF calculation model. LEMUF is computed using a formula to combine the error variances of all measurements, taking into account covariances among measurements. The user has options to model covariance to suit a particular application.

The simulated LEMUF is combined with a model of process losses and gains in the MUF simulation model. The results are simulated MUF values or distributions. The user has three options to model the losses and gains:

- a fixed loss rate,

- a variable loss or gain rate, and

- $\quad$ an aperiodic loss.

The simulated MUF or LEMUF data are compared using a hypothesis test for which the user selects the alarm threshold as a multiple of the LEMUF. The simulated data can also be analyzed using a cumulative summation (CUSUM) or state-estimation algorithms.

\section{ASM (AGGREGATED SYSTEMS MODEL)}

The ASM methodology 31,32 is being developed by Livermore and Applied Decision Analysis, Inc., for the NRC. It is designed to help the NRC set performance criteria for safeguards systems in licensed facilities. The philosophy closely parallels that expounded in "Societal Risk Approach to Safeguards Design and Evaluation," ${ }^{33}$ and indeed, the decision and event trees used in ASM appear to be essentially those shown in Fig. III of that report. The ASM method has the broadest scope of the methods reviewed, covering all functions of a comprehensive safeguards system--deterrence, prevention, detection, response, and recovery, as well as consideration of the complete adversary action sequence ranging from the decision to commit a malevolent act to the detonation of an IND or radioactive disposal device (RDD). Because the ASM philosophy includes consideration of societal risk, consequences of adversary actions are included.

ASM consists of a set of five submodels.

- Adversary Submodel. This is a probabilistic model of several kinds of adversaries, incorporating their attempt frequency, resources, and plan of attack. The model explicitly considers an adversary's choice of strategy such as the pathway to SNM, number of tries, quantity desired, and choice of tactics reflected in a decision to abort or continue a try if detected. The model assumes that the adversary makes these choices based on a 
preconceived notion of the possible outcome such as capture, success, or failure without capture.

- Facility Submodel. This model describes the system designed to safeguard SNM and the likelihood that each adversary will be detected and interrupted by the safeguards system.

- Safeguards Technology Submodel. This model describes safeguards components that could be incorporated in the safeguards design and their associated cost. Alternative designs for sensitivity analyses are considered.

- Consequences Submodel. This model is a probabalistic atatement of the effects of the malevolent uses of diverted SNM. Consequences were evaluated in terms of outcorries such as public fatalities, evacuation cost, and damage to the facility.

- Social Utility Submodel. Diversion consequences and safeguards costs are expressed in common units using the utility model. This would allow a decision maker to make explicit trade-offs among lives lost, property damage, evacuation cost, and the cost of safeguards.

Decision and event trees are constructed, based on the contents of these submodels. Probabilities for the branchings are assigned, based on professional judgment. As might be expected, many of these probabilities are purely speculative, because there is no data base from which to obtain guidance.

Such a highly aggregated, macroscopic view of safeguards systems seems to us to be of limited usefulness in determining effectiveness. However, with adequately substantiated values for the various assigned probabilities, the method might prove useful in influencing the following actions that the code developers presume the NRC must take.

- Set an acceptable performance level for individual components or for overall safeguards systems.

- Make trade-offs oetween safeguards components with different functions to achieve the most effective safeguards system, possibly within cost constraints.

- Find the socially optimal safeguards system with the best balance between the social need for safeguards and the social cost of the safeguards system.

The ASM code is incomplete. The NRC continues to fund its development. Even though ASM is proposed as an independent assessment code, the developers and the NRC see ASM as being coupled with a detailed assessment model, presumably the Structured Assessment Approach (SAA) also under development at Livermore. 


\section{SVAP (SAFEGUARDS VULNERABII ITY ANALYSIS PROGRAM)}

SVAP, one of the global, or macroscopic analytical techniques, was developed by Livermore under contract to the NRC. It is purported to be a technique that affords the analyst

...the capability to assess [the effectiveness of] any safeguards system against diversion of SNM by any combination of nonviolent insiders or outsiders.... The physical security and material accounting systems. are assessed for possible diversion paths.

The use of the word path is unfortunate in this context because the methodology is not one of the microscopic, or diversion path, techniques. SVAP provides only a series of plausible adversary action sequences that result in removal of SNM from the protected area. This is accomplished by computer manipulation of matrix modules derived from a general facility description. The matrixes account for an extensive, if not exhaustive, set of interactions among the structural features of the facility, the personnel and their authorizations, the target materials, the surveillance components of the safeguards system and the associated signal and utility lines, and the material accountability records and forms. No violent actions on the part of the adversary are allowed, limiting consideration to only the material control aspects of physical security. Like MAIT, SVAP examines the potential of insiders (and authorized outsiders), using their full access authorizations and authorizations that inhibit the safeguards component to remove SNM from the protected area. Detection, alarm assessment, and response probabilities are not included and are presumably left to the subjective judgment of the analyst. This is also true of MAIT.

Like all other global methodologies, SVAP is incomplete. The computer programs appear to be nontransferable and the methodology is nontransportable because large computers (CDC 7600s) are required. An evaluation based on SVAP would be at least a two-step procedure: data collection for matrix formation and matrix manipulation at a central computing facility. The matrix generation is accomplished by well-guided interactive graphics routines. Transmittal of input data via a MODEM from one microcomputer at the facility to another microcomputer connected to a CDC 7600 is presumably possible.

SVAP is now operational and has been applied to a portion of the General Electric fuel fabrication facility at Vallecitos.

The developers provide an idea of resource requirements for using SVAP. For example, they estimate that Building 332 at Livermore would require 3 months to evaluate, using a two-person team.

\section{SAA (STRUCTURAL ASSESSMENT APPROACH)}

$S A A^{34,35}$ was developed for the NRC by Livermore. The objective was to provide a methodology for determining the acceptability of an MC\&A system proposed by an applicant for a license to operate a fuel-cycle facility. The input information is that contained in a proposed license submittal document and in NRC data bases. The criteria for acceptability are based on 
performance tests; passing or failing is determined for four levels of increasingly stringent tests. This staging of the assessment allows for a measure of economy in analysis because failure at any level is cause for rejection of the MC\&A system as inadequate and the higher performance tests need not be made. The four levels of performance are indicated by the questions the levels pose.

Level 1. Can a nontampering adversary divert SNM with no risk of detection? Who is this adversary?

Level 2. Can a nontampering adversary divert SNM with some level of risk and does the probability of detecting that adversary meet NRC performance criteria?

Level 3. What system states, such as failed components or collusion among employees and adversaries, would allow the adversary to divert SNM? Does the system meet single-failure criteria?

Level 4. Can the adversary tamper with the system--both through altering physical systems and through colluding with others--to divert SNM without detection?

SAA is perhaps the most sophisticated and complex of all the MC\&A assessment methodologies. An analytical methodology, it relies on a massive amount of input data for an adequate assessment. Because SAA relies on such complete input and is an analytical method, it has the potential for providing a great deal of analysis with a minimum of subjective intervention on the part of the analyst. It is easy to see how such a methodology would be suitable for the NRC. It provides for a uniform assessment tool with standard output, defensible rationale for rejection of license applications, and, perhaps of paramount importance, is based on a performance measure examination of a standardized license submittal document. In the regulation arena these characteristics are highly desirable. However, this methodology appears to be too oriented towards NRC requirements to be applied to DOE facilities; the issue here is not comparability, but rather the information formatting required for adherence to NRC regulations.

The SAA code uses event tree algorithms and runs on the Livermore CDC 7600 computer. The SAA methodology was applied to a portion of hypothetical Facility $X$. The resource requirement for this limited application was estimated to be 9 man-weeks.

\section{CEP (COMPREHENSIVE EVALUATION PLAN)}

The 1977 NRC Comprehensive Evaluation Plan ${ }^{36}$ separated an evaluation into two basic categories: capability assessments and vulnerability appraisals. The capability assessment category was subdivided into two types of evaluations: material accountability assessments and physical security assessments. The discussion of the approach to physical security assessments appears under the heading "Utility Theory Approach." The NRC intends to synthesize the results of both assessments with the results of a vulnerability appraisal to determine the adequacy of a licensee's safeguards system. 
The objective of the material accountability assessment is to determine the capabilities of that function in the integrated system. Two fundamental adequacy questions are addressed in the assessment. (a) Is the information content of the MC\&A subsystem adequate for prevention of diversion, through timely detection and response, of a quantity of SNM over a period of time by a number of employees (all specified) by either an abrupt or protracted strategy? (b) Can the MC\&A system provide assurance that no SNM greater than a specified amount could have been diverted during the specified time?

A disaggregation of questions originates from the basic questions and covers four levels of safeguards system structure, or hierarchy. The first level consists of the MC\&A system for bulk materials and the MC\&A system for discrete items; the second consists of the subsystems of each of these systems; the third consists of the components of these subsystems; and the fourth consists of the characteristics of these components. A complete set of questions is thus available for the assessment team to use. After the assessment team provides responses to the questionnaire, an aggregation of these responses is done through the levels to arrive at an overall score for the MC\&A adequacy.

This approach has merit in that it guides the assessor through the requisite examination of the system hierarchy. The number of questions is large, but tractable. Because the number of questions is finite, however, one concludes that individual question responses are themselves the result of an innate aggregation carried out in the mind of the assessor. Thus, the mental aggregation ability of the assessor has some impact on the outcome. This can be thought of as the subjective nature of responses to questions that involve value jugements of component characteristics. The questionnaire represents a standard set so that, with an invariant team of assessors, uniformity of application could be claimed. All NRC-Jicensed, nonreactor, fuel-cycle facilities were subjected to such an assessment during 1977-1978.

No computer assistance is needed for the use of such a methodology. It shares a great deal of philosophical base with DPA but is not nearly as formalized.

\section{LOS ALAMOS DESIGN AND EVALUATION METHODOLOGY}

The Los Alamos National Laboratory developed several conceptual designs and evaluation methodologies for advanced safeguards systems for the DOE. These methodologies were designed to determine the diversion or loss sensitivity of material accountability systems based on the performance measures of the system. Because of the statistical nature of materials accountability, diversion sensitivity is described in terms of the probability of detecting some level of diversion, while accepting some probability of a false alarm. The indication of a statistically significant materials imbalance is a necessary part of any definition of detection.

The usual procedure is to define three performance measures: the probability of detection, the total diversion, and the time over which the diversion occurs until it is detected. Whether the diversion occurs in an abrupt or protracted fashion is not a factor in the performance measure. The total amount diverted is the important characteristic. 
Using statistical techniques, one can show that the three performance measures are interrelated by a family of continuous functions that depend on the details of each particular safeguards system. Thus, a convenient way of displaying the capability of a system is a three-dimensional graph of detection probability versus total loss and time. Such a graph is called a performance surface.

The overall performance surface for materials accountability in a facility depends on both the materials measurement system and on the statistical techniques use $d$ to analyze the materials accountability data. Details of a comprehensive set of statistical methodologies appear in Refs. 37-41. These methods are used extensively in Los Alamos systems studies and are beginning to be used for analysis of actual materials accountability data at several facilities.

For a host of reasons, including cost, time, and the unavailability and inflexibility of operating facilities, computerized modeling and slmulation of the facilities and safeguards systems are indispensable tools in developing and analyzing advanced safeguards systems.

For materials accountability, the modeling and simulation approach requires a detailed dynamic model of the process based on actual process design data. Design concepts are evolved by identifying key measurement points and appropriate measurement techniques, comparing possible materials accountability strategies, developing and testing appropriate data analysis algorithms, and quantitatively evaluating the capability of the proposed materials accountability system to detect losses. By using modeling and simulation techniques, the effects of process and measurement variations over long operating periods and for various operating modes can be studied in a short time.

Computer codes have been developed to simulate the operation of each model process using standard Monte Carlo techniques. Input data include initial values for all process variables and values of statistical parameters that describe each independent stochastic process variable. These data are best estimates obtained from process designers and operators. Each unit process is modeled separately. When a process event occurs in a particular unit process, the values of SNM flows and in-process inventories associated with that unit process are computed and stored in a data matrix. These data are available for further analysis and as input to computer codes that simulate accounting measurements and material balances.

The SNM flow and inventory quantities from a process model are converted to measured values by making simulated measurements. Each measurement type is modeled separately; measurement errors are assumed to be narmally distributed, and provisions are made for both additive (absolute) and multiplicative (relative) errors. Significant measurement correlations are included explicitly. In most cases, the measurement models are derived from the performance of similar instrumentation characterized in both laboratory and field applications for similar materjals. Simulated measurements are combined to form material balances under various strategies for nearreal-time material accountability. 
The most promising measurement and accountability strategies are combined with powerful statistical techniques in comparative studies of lossdetection sensitivities. The result is a set of performance surfaces, similar to those described previously, that represent the capabilities of the system.

\section{LIVERMORE DESIGN AND EVALUATION METHODOLOGY}

Livermore is under contract to the NRC to provide computational tools for assessing MC\&A systems. Three computer codes were developed for application in designing and assessing what Livermore calls processmonitoring components. A process munitor is a device that makes measurements of physical parameters and then processes these measurements to make a material loss decision. The MC\&A assessment methodology under development at Livermore requires information in the form of performance models of various MC\&A components.

To characterize the performance capability of a process monitor, mathematical models of the physical phenomenology and its associated measurement system are developed. If the process monitor being assessed includes an estimation filter (for example, a computer algorithm) to improve signal-tonoise ratios or to extract optimum estimates of the process variables of interest, then an additional requirement is to describe the performance of various estimation filters. Finally, the performance of the decision device or detector associated with the process monitor is characterized.

Among the codes developed are (a) DYNSYL ${ }^{42}$ (Dynamic Simulator), a general-purpose dynamic simulator for modeling the physical phenomenology of various chemical unit operations and their associated measurement systems; (b) DYNEST ${ }^{43}$ (Dynamic Estimator), an estimation code for simulating the operation of some modern signal-processing algorithms (Kalman filter formulation); and (c) DDET $T^{44}$ (Dynamic Detector), a set of detection algorithms for simulating on-line material loss detection algorithms. These codes can be used to address the issues of on-line material accountability and diversion detection for safeguarding SNM, specifically with respect to arriying at meaningful performance measures. The dynamic simulation, continuous in time, provides solutions to a large number of simultaneous interdependent differential equations that are written to describe the chemical processes. The method requires that all relevant equations for the process being described be ircluded. Such equation-oriented codes with complete equation coupling ensure the greatest dynamic simulation accuracy, particularly for large time steps, but require common computer storage for all derivative or variable values for all integration steps. This requirement imposes severe limits on the number of plant units that may be simulated in a continuous fashion. A limited/number of process unit modules have been developed.

In contrast with this approach, the Los Alamos methodology uses computer simulation in the discrete time interval class that simulates inventory and material flows in the plant. The economy of this type of event simulation is such that the entire process line simulation is tractable. As a result, the Los Alamos methodology has been applied to a number of complete systems, whereas the Livermore methodology has been applied to only a few components of a system. 


\section{REFERENCES}

1. R. W. Perry, C. A. Bennett, and M. T. Wood, "The Role of Security Clearances and Personnel Reliability Programs in Protecting Against, Insider Threats," Battelle Human Affairs Research Center's repcrt B-HARC-411-018 (1979).

2. L. G. Gref and L. W. Rosengren, "An Assessment of Some Safeguards Evaluation Techniques," R\&D Associates RDA-TR-5000-002 (1977); NUREG-0141.

3. R. B. Davidson and L. W. Rosengren, "An Assessment of Current Physical Security Models," R\&D Associates RDA-TR-1 1500-001 (1979).

4. J. P. Shipley, "Some Safeguards Approaches and Evaluation Methods," Nuclear Materials Management VIII (4), 58-65 (1980).

5. L. R. Beres, "Hic Sunt Dracones: The Nuclear Threat of International Terrorism," Parameters, Journal of the US Army War College IX (2), 11 (1979).

6. S. Baloga, "The Classical Inventory Verification Concept," National Bureau of Standards letter of transmittal with unpublished report from S. Baloga to E. Dowdy, November 17, 1981.

7. H. A. Bennett, "The EASI Approach to Physical Security Evaluation," Sandia Laboratories report SAND 76-0500 (1977); NUREG-760145.

8. D. Engi and C. P. Harlan, "Brief Adversary Threat Loss Estimetox (BATLE) User's Guide," Sandia National Laboratories report 'SAND $78-1136$ (1981); NUREG/CR-1432.

9. L. D. Chapman, G. A. Kinemond, and D. W. Sasser, "Users Guide' for Evaluating Alternative Fixed-Site Physical Protection Systems Using FESEM," Sandia Laboratories report SAND 77-1367 (1977).

10. L. D. Chapman, L. M. Grady, H. A. Bennett, D. W. Sasser, and D. Engl, "Safeguards Automated Facility Evaluation (SAFE) Methodology," Sandia Laboratories report SAND 78-0378 (:-78); NUREG/CR-0296.

11. L. D. Chapman, H. A. Bennett, D. Engi, L. M. Grady, B. L. Hulme, and D. W. Sasser, "Safeguards Methodalogy Development History," Sandia Laboratories report SAND 79-0059 (1979); NUREG/CR-0788).

12. D. W. Swindle, "The Use of Effectiveness Evaluation in the Design of a Physical Protection System for the Consolidated Fuel Reprocessing Program's Hat Experimental Facility," 20th Annual Meeting of the Institute of Nuclear Materials Management, Albuqueraue, NM, July 16-18, 1979; Nuclear Materials Management VIIl, 761 (1979).

13. F. H. Grant, R. 3. Miner, and D. Engi, "A Network Modeling and Analysis Technique for the Evaluation of Nuclear Safeguards Effectiveness," Sandia Laboratories report SAND 78-0671 (1979); NUREG/CR-0616. 
14. L. D. Chapman and D. Engi, "Safeguards Network Analysis Procedure (SNAP) - Overview," Sandia Laboratories report SAND 79-0438 (1979); NUREG/CR-0960.

15. 3. C. Sandierlin and C. E. Rathman, "A Concept for Assessment of Physical Security System Performance - Phase I," Mission Research Corporation report MRC-7850-1-1278 (1978).

16. H. A. Bennett and M. T. Olascoaga, "An Evaluation Methodology Based on Physical Security Assessment Results - A Utility Theory Approach," Sandia Laboratories report SAND 78-0377 (1978).

17. H. Dannelly, R. Fullwood, and J. Glancy, "VISA: A Method for Evaluatirig the Performance of Integrated Safeguards Systems at Nuclear Facilities," Science Applications, Inc., report SAI-77-590-LJ (1977); NUREG-0317.

18. L. Kull, L. Harris, Jr., and J. Glancy, "VISA - A Method for Evaluating the Performance of a Facility Safeguards System," Nuclear Materials Management IV (3), 292 (1977).

19. D. D. Boozer and D. Engi, "Simulation of Personnel Control System with the Insider Safeguards Effectiveness Model (ISEM)," Sandia Laboratories report SAND 76-0682 (1977).

20. D. D. Boozer and D. Engi, "Insider Safeguards Effectiveness Model (ISEM) Users Guide," Sandla Laboratories report SAND 77-0043 (1977).

21. D. Engi, "A Small-Scale Engagement Model with Arrivals: Analytical Solutions," Sandia Laboratories report SAND 77-0054 (1977).

22. T. L. McDaniel, L. Huszar, and J. E. Glancy, "Matrix Analysis of the Insider Threat," 20th Annual Meeting of the Institute of Nuclear Materials Management, Albuquerque, New Mexico, July 16-18, 1979; Nuclear Materials Management VIII, 769-776 (1979).

23. T. L. McDaniel, J. E. Glancy, and W. H. Horton, "Safeguards Against Insider Collusion, Vol. I: Guide on the Design of Work Rules for Safeguarding Against the Employee Collusion Threet at Nuclear Fuel Facilities," Science Applications, Inc., report SAI-78-996-LJ (1978); NUREG/CR-0532.

24. T. L. McDaniel and L. Huszar, Jr., "Safeguards Against Insider Collusion, Vol. 2: The MAIT (Matrix Analysis of the Insider Threat) Method for Analysis of Facility Safeguards Against Insider Collusion - User's Manual," Science Applications, Inc., report SAI-78-960-LJ (1979); NUREG/CR-0532.

25. J. Glancy, J. Nicastro, W. Woolson, and A. El-Bassioni, "Analysis of Nuclear Fuel Facility Safeguards Against Threats Involving Insider Collusion, Science Applications, Inc., report SAI-78-547-LJ (1978).

26. K. E. Goodwin, J. C. Schleter, and M. D. K. Maltese, "Diversion Path Analysis," National Bureau of Standards report NCP/D6010-01/1-4 (1978). 
27. C. M. Schaumann, C. N. Stanford, and R. S. Thomason, "Diversion Path Analysis at Savannah River Plant," 19th Annual Meeting of the Institute of Nuclear Materials Management, Cincinnati, Ohio, June 27-29, 1978; Nuclear Materials Management VII (1), 140 (1978).

28. J. C. Schleter and K. E. Goodwin, "Initial Diversion Vulnerability Assessment;" National Bureau of Standards report SIRM-86 (1977).

29. W. E. Siri, J. F. Wimpey, J. T. Powers, and J. E. Glancy, "Material Unaccounted for Performance Analysis of a US Nuclear Regulatory Commission Licensee," US Nuclear Regulatory Commission report NUREG/CR-0083 (1979).

30. F. Wimpey and M. Messinger, "Applications of a Material Accounting Model," 20th Annual Meeting of the Institute of Nuclear Materials Management, Albuquerque, New Mexico, July 16-18, 1979; Nuclear Materials Management VIII, 807 (1979).

31. R. Al-Ayat and B. Judd, "Aggregated Systems Model of Nuclear Safeguards, Vol. 1, Executive Summary," Lawrence Livermore National Laboratory report UCRL-52712-Vol. 1 (1979); NUREG/CR-1140.

32. R. Al-Ayat and B. Judd, "The Aggregated Systems Model--A Tool for Nuclear Safeguards Decision Making," Transactions of the American Nuclear Society 33, 438 (1979).

33. C. A. Bennett, W. M. Murphy, and T. S. Sherr, "Societal Risk Approach to Safeguards Design and Evaluation," US Energy Research and Development Agency report ERDA-7 (1975).

34. A. A. Parziale, 1. J. Sacks, T. R. Rice, and S. L. Derby, "The Structured Assessment Analysis of Facility X, Vol. I: Executive Summary," Lawrence Livermore National Laboratory report UCRL-52765 (1979); NUREG/CR-079l.

35. A. A. Parziale and I. J. Sacks, "Procedure for the Assessment of Material Control and Accounting Systems," Lawrence Livermore National Laboratory report UCRL-82213 (1979).

36. Staff, "1977 Comprehensive Evaluation Plan (Fuel Cycle Facilities with SSNM)," US Nuclear Regulatory Commission (1977).

37. J. P. Shipley, D. D. Cobb, R. J. Dietz, M. L. Evans, E. P. Schelonka, D. B. Smith, and R. B. Walton, "Coordinated Safeguards for Materials Management in a Mixed-Oxide Fuel Facility," Los Alamos Scientific Laboratory report LA-6536 (1977).

38. E. A. Hakkila, D. D. Cobb, H.A. Dayem, R. J. Dietz, E. A. Kern, E. P. Schelonka, J. P. Shipley, D. B. Smith, R. H. Augustson, and J. W. Barnes, "Coordinated Safeguards for Materials Management in a Fuel Reprocessing Plant," Los Alamos Scientific Laboratory report LA-688!, Vol.? (1977). 
39. H. A. Dayem, D. D. Cobb, R. J. Ditz, E. A. Hakkila, E. A. Kern, J. P. Shipley, D. B. Smith, and D. F. Bowersox, "Coordinated Safeguards for Materials Management in a Nitrate-to-Oxide Conversion Facility," Los Alamo Scientific Laboratory report LA-701 1 (1978).

40. H. A. Dayem, D. D. Cobb, R. J. Diets, E. A. Hakkila, J. P. Shipley, and D. B. Smith, "Dynamic Materials Accounting in the Back End of the LWR Fuel Cycle," Nuclear Technology 43, 222-243 (1979).

41. J. P. Shipley, "Conceptual Design of Integrated Safeguards Systems," Nuclear Materials Management VI (3), 111-124 (1977).

42. G. K. Patterson and R. B. Rozsa, "DYNSYL: A General Purpose Dynamic Simulator for Chemical Processes," Lawrence Livermore National Laboratory report UCRL-52561 (1978).

43. R. Castleton and J. V. Candy, "DYNEST--A Dynamic Estimator Calculation Program," Lawrence Livermore National Laboratory report UCRL-52573 (1978).

44. G. Myers, "DDET: A Program Which Simulates On-Line Detectors," Lawrence Livermore National Laboratory report UCRL-18106 (1979).

39 


$\begin{array}{ll}\text { AGNS } & \text { Allied General Nuclear Services } \\ \text { ASM } & \text { Aggregated Systems Model } \\ \text { BATLE } & \text { Brief Adversary Threat Loss Estimator } \\ \text { BPID } & \text { book-physical inventory difference } \\ \text { CEP } & \text { Comprehensive Evaluation Plan } \\ \text { CUSUM } & \text { cumulative summation } \\ \text { DDET } & \text { Dynamlc Detector } \\ \text { DOD } & \text { Department of Defense } \\ \text { DOE } & \text { Department of Energy } \\ \text { DPA } & \text { diversion path analysis } \\ \text { DYNEST } & \text { Dynamic Estimator } \\ \text { DYNSYL } & \text { Dynamic Simulator } \\ \text { EASI } & \text { Estimate of Adversary Sequence Interruption } \\ \text { FESEM } & \text { Forcible Entry Safeguards Effectiveness Model } \\ \text { GDP } & \text { general diversion path } \\ \text { GPPLT } & \text { Generic Physical Protection Logic Tree } \\ \text { IDVA } & \text { Initial Diversion Vulnerability Assessment } \\ \text { IND } & \text { improvised nuclear device } \\ \text { ISEM } & \text { Insider Safeguards Effertiveness Model } \\ \text { LEMUF } & \text { limit of error for material unaccounted for } \\ \text { MAA } & \text { material access area } \\ \text { MAIT } & \text { Matrix Analysis of the Insider Threat } \\ \text { MBA } & \text { material balance area } \\ \text { MC\&A } & \text { material control and accountability } \\ \text { MCLAMS } & \text { Measurement Control, LEMUF, and MUF Simulation } \\ \text { MUF } & \text { material unaccounted for } \\ \text { NBS } & \text { National Bureau of Standards } \\ \text { NRC } & \text { Nuclear Regulatory Commission } \\ \text { OSS } & \text { Office of Safeguards and Security } \\ \text { PA } & \text { protected area } \\ \text { RDA } & \text { R\&D Associates } \\ \text { RDD } & \text { radioactive disposal device } \\ \text { SAA } & \text { Structured Assessment Approach } \\ \text { SAFE } & \text { Safeguards Automated Facility Evaluation } \\ \text { SAI } & \text { Science Applications, Inc. } \\ \text { SDP } & \text { specific diversion path } \\ \text { SMART } & \text { Safeguards Management Analytical Risk Tree } \\ \text { SNAP } & \text { Safeguards Network Analysis Procedure } \\ \text { SNM } & \text { special nuclear material } \\ \text { SSPAM } & \text { Security System Performance Analysis Methodology } \\ \text { SVAP } & \text { Safeguards Vulnerability Analysis Program } \\ \text { VISA } & \text { Vulnerability of Integrated Safeguards Analysis } \\ & \end{array}$

